\title{
Conservative Treatment of a Placenta Accreta Case: Partial Segmental Uterine Resection
}

\author{
Hicran Acar', Fatma Ferda Verit ${ }^{2}$, Seyda Baydogan ${ }^{2}$, Orkun Cetin ${ }^{3 *}$, Mertihan Kurdoglu ${ }^{3}$
}

\begin{abstract}
Introduction: Placenta accreta $(\mathrm{PA})$ is defined as the penetration of trophoblastic tissue into the myometrium. We aimed to report a case of PA which was successfully managed with partial segmental resection of uterus.

Case Presentation: A 23 years old women gravida 2, parity 1, referred to our hospital for placental retention after vaginal delivery. The intraoperative exploration showed that the placenta remained in the right part of the uterine. According to these findings, the initial diagnosis was PA. The placenta and the uterine wall were removed in one piece. The uterine wall was reconstructed by vicyrl no: 1 in a three layer closure. Bilateral uterine artery ligation was performed in order to prevent excess uterus bleeding. Then, modified b-lynch suture was performed for prophylaxis of atonia.

Conclusion: Nowadays, conserving the uterus, avoiding the possibility of hemorrhage and making future pregnancies possible are the main objectives of conservative treatments in PA. Partial segmental uterine resection is an alternative, conservative and acceptable management option in selected cases of PA.

Keywords: Placenta accreta, Conservative treatment, Segmental resection
\end{abstract}

\section{Introduction}

Abnormal placentation is associated with increased maternal morbidity and mortality. Placenta accreta (PA) is one of the most feared complications in obstetrics; it occurs when the placenta is abnormally adherent to the uterus. PA is defined as the penetration of trophoblastic tissue into the myometrium. The incidence of PA has been reported to be as much as one in 533 pregnancies, based on Wu et al study (1). PA can lead to serious preoperative, intraoperative, and/or postoperative bleeding. Treatment options for postpartum hemorrhage include conservative management with uterotonic drugs, selective devascularization by ligation or embolization of the uterine artery, external compression with uterine sutures (B-Lynch, Hayman, Cho), and intrauterine packing (2). The usual surgical approach would involve selective ligation of the ascending uterine arteries above the cervical isthmus. The technically more demanding hypogastric artery ligation may then be considered, if bleeding persists (3). Severe hemorrhage can be life threatening, and often a hysterectomy is required. Since this leads inevitably to loss of fertility, a fertility sparing approach is desirable. Accordingly, conservative management is sometimes considered as an option today, except in cases of heavy hemorrhage or disseminated intravascular coagulation. We aimed to report a case of PA which was successfully managed with partial segmental resection of uterus.

\section{Case Presentation}

A 23 years old woman referred to our medical center with diagnosis of retained placenta following vaginal delivery. On admission, ultrasound examination showed that the placenta has covered the right part of the uterus and there was no retroplacental clear zone. Multiple attempts were made at manual removal but we were unable to remove the placenta from uterus. Patient was taken to the operating room for manual removal and possible curettage under general anesthesia. All attempts were failed. The intraoperative exploration showed that the placenta remained in the right part of the uterine (Figure 1). According to these findings, the initial diagnosis was PA. It was not possible to remove the placenta without uterine resection. The placenta and attached uterine wall resected together. The residual uterine wall was repaired by no: 1 vicryl with three layer closure (Figure 2). Bilateral uterine artery ligation and modified b-lynch suture were applied for the prevention of uterine bleeding and atonia. Postoperative hemoglobin value was $12.1 \mathrm{~g} / \mathrm{dl}$. The patient was discharged 3 days after surgery without any complication. Pathological examination confirmed the initial diagnosis of PA.

\section{Discussion \\ PA occurs when there is a defect in the decidua basalis, resulting in abnormally invasive implantation of placenta. The important risk factors of PA include placenta previa and previous uterine cesarean scarring. The PA risk is 3\% in uterus which does not contain placenta previa and cae- sarean scar (4). Management methods of PA have been described ranging from conservative methods to hysterec-}

Received 8 June 2015, Accepted 20 November 2015, Available online 12 December 2015

${ }^{1}$ Department of Obstetrics and Gynecology, Zeynep Kamil Education and Research Hospital, Istanbul, Turkey. ${ }^{2}$ Department of Obstetrics and Gynecology, Süleymaniye Education and Research Hospital, Istanbul, Turkey. ${ }^{3}$ Department of Obstetrics and Gynecology, Yüzüncü Yll University, Faculty of Medicine, Van, Turkey

*Corresponding author: Orkun Cetin, Tel: 04322150574, Email: drorkuncetin34@hotmail.com 


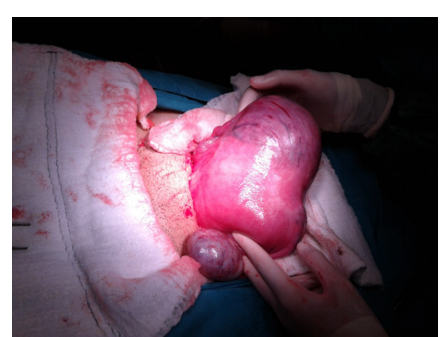

Figure 1. Placenta Accreta (PA) Located in the Right Part of the Uterus.

tomy. The decision was taken because it was not possible to perform a puerperal hysterectomy. Nowadays, conserving the uterus, avoiding the possibility of hemorrhage and making future pregnancies possible are the main objectives of conservative treatments in PA (5). There has been a gradual shift towards conservative management of PA with the main aim to preserve the future fertility. There are two main conservative options. The first alternative was retaining the attached part of placenta for later reabsorption day by day. The other possible alternative was resecting the attached area together and repairing residual part of the uterus. PA and its varieties produce damage of the invaded tissues (uterus and others) by developing new vascularization and pelvic anatomic distortion. These problems can be solved in different ways, and have led to the development of new techniques (6). The conservative method was first described by Arulkumaran et al (7). They reported a case of PA successfully treated with intravenous methotrexate. Another option for the conservative treatment of PA is endovascular approaches occluding the internal iliac arteries through embolizationballoons (8). However, the placenta left in situ can be associated with risks of sepsis and delayed hemorrhages (9). Primary surgery repair by a large retrovesical and parametrial resection in anterior PA has been reported in a study by Palacios-Jaraquemada et al (10). The anterior wall defect was repaired using polyglycolic mesh and fibrin glue. Another conservative treatment, the left placenta and the uterine wall were removed in one piece in a study by Simsek et al (11). Partial segmental uterine resection is an alternative, conservative and acceptable management option in selected cases of PA.

\section{Ethical Issues}

The authors have obtained permission before using patient data and images.

\section{Conflict of Interests}

Authors declare that they have no competing interests.

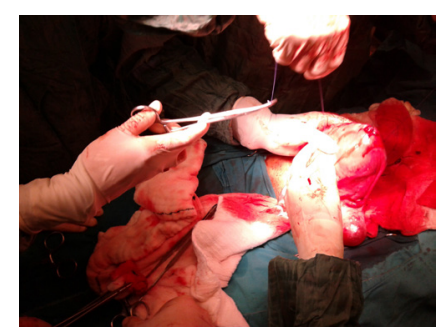

Figure 2. Segmental Partial Resection of the Uterus and Reconstruction of the Uterine Wall by no:1 Vicryl.

\section{Acknowledgments}

None to be declared.

\section{References}

1. Wu S, Kocherginsky M, Hibbard JU. Abnormal placentation: twenty-year analysis. Am J Obstet Gynecol 2005;192:145814-61. doi: 10.1016/j.ajog.2004.12.074

2. B-Lynch C, Coker A, Lawal A, Abu J, Cowen M. The B-Lynch surgical technique for the control of massive postpartum hemorrhage: an alternative to hysterectomy? Five cases reported. Br J Obstet Gynaecol. 1997;104 (3):372375. doi:10.1111/j.1471-0528.1997.tb11471.x.

3. Stone K. Acute abdominal emergencies associated with pregnancy. Clin Obstet Gynecol. 2002;45(2): 553-561.

4. Silver RM, Landon MB, Rouse DJ, et al. Maternal morbidity associated with multiple repeat cesearean deliveries. Obstet Gynecol. 2006;107(6):1226-1232.doi:10.1097/01. AOG.0000219750.79480.84

5. Palacios-Jaraquemada JM. Diagnosis and management of placenta accreta.Best Pract Res Clin Obstet Gynaecol. 2008;22(6):1133-48. doi:10.1016/j.bpobgyn.2008.08.003.

6. Palacios-Jaraquemada JM. Caesarean section in cases of placenta praevia and accreta. Best Pract Res Clin Obstet Gynaecol 2013;27(2):221-232. doi:10.1016/j. bpobgyn.2012.10.003.

7. Arulkumaran S, Ng CS, Ingemarsson I, Ratnam SS. Medical treatment of placenta accreata with methotrexate. Acta Obstet Gynecol Scand. 1986;65:285-286.

8. Tong SY, Tay KH, Kwek YCK. Conservative management of placenta accreta: review of three cases. Singapore Med. 2008;49(6):156-159.

9. Butt K, Gagnon A, Delisle MF. Failure of methotrexate and internal iliac balloon catheterization to manage placenta percreta. Obstet Gynecol. 2002;99(6):981-982.

10. Palacios Jaraquemada JM, Pesaresi M, Nassif JC, et al. Anterior placenta percreta: surgical approach, hemostasis and uterine repair. Acta Obstetricia Gynecol Scand. 2004;83:738-744. doi:10.1111/j.0001-6349.2004.00517.x.

11. Simsek T, Saruhan Z, Karaveli S. Placenta percreta: conservative treatment - segmental uterine resection with placenta in one piece. J Obstet Gynaecol. 2010;30(7):735736. doi: 10.3109/01443615.2010.501918.

\section{Financial Support}

None to be declared.

\footnotetext{
Copyright (c) 2016 The Author(s); This is an open-access article distributed under the terms of the Creative Commons Attribution License (http://creativecommons.org/licenses/by/4.0), which permits unrestricted use, distribution, and reproduction in any medium, provided the original work is properly cited.
} 